\title{
Brave blue world
}

\section{Human spaceflight is no excuse for ignoring the home planet, which needs constant monitoring from space.}

$$
\text { a }
$$
$\mathrm{t}$ is commonplace to dismiss NASA's human spaceflight efforts as a waste of money and expertise. For a country with an alarming budget deficit to devote tens of billions of dollars to a project with so little prospect of palpable returns is hard to justify. Certainly, science does not come close to offering a justification.

But arguments against this peculiarly pricey form of showing off, however strong, will not prevail in the foreseeable future. Space exploration resonates with the expectations many Americans have of their country as a home to the exceptional, a conqueror of frontiers and a leader of the world.

Furthermore, the inspiring, potentially transcendent impact of human spaceflight on the imagination should not be lightly dismissed. In the words of one uplifted pioneer: "In that instant I could feel no doubt of man's oneness with the universe... It was a feeling that transcended reason; that went to the heart of man's despair and found it groundless. The universe was a cosmos, not a chaos; man was rightfully a part of that cosmos as were the day and night."

The pioneer quoted above was not an astronaut, although he got as close to the alien isolation of space as any man could at the time. $\mathrm{He}$ was the US Antarctic explorer Richard Byrd. As NASA administrator Michael Griffin has argued, there are some interesting parallels to be drawn between the history of Antarctic exploration and the possible future for American spaceflight. But there are differences, too, to which NASA, the Bush administration and Congress should pay careful attention.

Griffin points out that after the South Pole was first explored, it was largely ignored for decades before an eventual return in the 1957 International Geophysical Year led to a continuous presence. Similarly, NASA's plans now call for ending the post-Apollo hiatus by setting up a permanent lunar base - probably at the south pole. But there the comparisons end. For one thing, the renewal of Antarctic exploration was empowered by new technologies, notably reliable diesel engines, capable aircraft and portable radios. But the technologies that NASA plans to implement on its return to the Moon look

\section{Defence deficit}

\section{A public debate about renewing Britain's nuclear weaponry is undermined by excessive secrecy.}

\footnotetext{
The RS21007 document could have featured in a John le Carré spy novel. The author of its six drily written pages discusses a plan to turn nudear submarines into cruise-missile carriers. It is a detailed analysis, probing issues such as exactly which firing tubes would need to be modified. In Britain, it is unlikely that such matters would be discussed outside classified government meetings or clandestine get-togethers between le Carrés fictional spies.
}

remarkably similar to those it used the first time (see page 474).

Another difference is that ever since humanity's return to the South Pole, Antarctic science has been central to the great project of understanding the changes that humans are inflicting on the Earth. An Antarctic component to the nascent global carbon dioxide monitoring effort was established in 1957. Since then the contributions have been legion: discovery of the Antarctic ozone hole; the extraction of greenhouse-gas records and climate data reaching back more than half-a-million years from ice cores; the study of the anomalous warming of the Antarctic peninsula; and so on.

Although lunar research may illuminate some far deeper recesses of Earth's history, the Moon is no Antarctica: the onlyinput that lunar activity will provide for the study of Earth is the iconic and inspiring sight of a blue planet in a black sky over a grey desert.

The human exploration of new worlds may well be important, as inspiration and even, eventually, as something more. But it is not urgent in the same way as understanding and monitoring the Earth system. This is why, as the amount NASA spends on its new vision of exploration increases, it is vital that the resources needed to monitor and study Earth are brought up to the levels required, from which
"The only input that lunar activity will provide for the study of Earth is the iconic sight of a blue planet in a black sky over a grey desert." funding currently falls short. As a report by the National Academy of Science recently pointed out, some of this remediation needs to take place at the National Oceanic and Atmospheric Administration, where various instruments need to be placed on future weather satellites or flown on other platforms. But there are also challenges for NASA, notably in studying land-use change and global precipitation, that need to be seen as high priorities for the immediate future.

Mapping the march of global change and exploring possible futures have an urgency that the study of eternal verities and ancient deserts cannot match. The Moon is not going anywhere; Earth is.

Yet the origins of RS21007 are mundane: its authors are a group of uncontroversial public officials working at the US Congressional Research Service (CRS). The level of detail is not unusual for such a report. In the United States, RS21007 is seen as a useful contribution to the debate about the country's military capabilities. Had the document been written in Britain, it might never have seen the light of day. And that's a problem - without such documents it is impossible to properly scrutinize government proposals.

The proposal that matters right now, and which is currently being studied under conditions of information poverty (see page 464), is an important one. Britain's Trident submarines carry the country's nuclear weapons. The end of their design life is around 15 years away. What comes next? The government favours building a new fleet, at 
a cost of up to $£ 20$ billion (US $\$ 40$ billion), and a parliamentary vote is expected next month.

Submarine builders and the military say that replacing the fleet will ensure that Britain can deter nuclear attacks and avoid the expensive repair costs associated with old vessels. Lining up against them are various weapons experts and think-tanks who argue that the submarines' working lives could be extended by up to 20 years. That would give the government time to better assess whether a system designed for the cold war is really the right defence for a world where rogue nuclear states and terrorists are the biggest threats.

Which side is correct? Unhappily, Nature has to admit ignorance on this point. Just a few pages of the relevant White Paper were devoted to the issue of replacement versus repair. Attempts by think-tanks to prise information from the Ministry of Defence have failed. A document like RS21007 would have gone a long way towards helping assess the options. Yet no such document exists and there are no plans for one to be published before the vote takes place.

The debate would be more robust if Britain took the US approach, of which the CRS is a relatively minor component. More important are the scientific experts who are given security clearance. Congressional committees have access to information, can interrogate officials and pass judgements, in public and in private, on classified programmes. Non-profit groups such as the Natural Resources Defense Council have accumulated considerable knowledge on nudear matters and frequently engage the federal government in lively and informed public debate. The National Academy of Sciences is also used by the government as a sounding board for security issues, and many reports are published in unclassified form.

In Britain, the gulf between the Ministry of Defence and academia is far wider, partly because of the over-secretive culture of the civil service. But there is little reason why this should be so. If Britain is to properly evaluate the threat it faces, outside experts need to join the debate. Groups such as the Royal Society and the Royal Academy of Engineering would be obvious first points of contact, and both organizations could do more to make the case for their being involved.

The United States has shown that publicscrutiny of critical defence expenditures needn't hand its enemies critical secrets. Britain can learn to do the same.

\section{A changing drug supply}

Research cuts by the world's largest drug company reflect a challenging outlook for the industry.

D fizer's announcement last week that it will cut its research marks a watershed for the pharmaceutical industry (see page 466). Until now Pfizer, the leading drug company in terms of both sales and research spending, and an important industry bellwether, has refrained from cutting its efforts to discover new drugs. Yet its $\$ 7$ billion in annual R\&D expenditures has failed to generate anything near the number of discoveries needed to cover those costs.

The problems facing Pfizer also affect the rest of the industry. A November report by the US Government Accountability Office found that while the industry's US R\&D spending rose by 147\% from 1993 to 2004, applications for drug approvals to the US Food and Drug Administration rose by only $38 \%$. Applications for drugs with ingredients never before marketed in the United States grew by just 7\%.

Former Pfizer chief executive Hank McKinnell found a fix by buying blockbusters instead of discovering them. The acquisition in 2000 of Warner-Lambert gave Pfizer the cholesterol-lowering drug Lipitor, with almost $\$ 13$ billion in 2006 sales. In 2003, Pfizer bought Pharmacia and with it the arthritis drug Celebrex, which brought in around $\$ 2$ billion last year.

But last summer, Pfizer's board ousted McKinnell in a clear signal of its impatience with that strategy's lack of longer-term delivery, compounded by its concern about the spectre of expiring patents. Five Pfizer drugs worth nearly $\$ 9$ billion a year will lose patent protection before Lipitor goes off-patent four years from now. The board wants a change in the firm's R\&D strategy and allocation of resources. With new chief executive Jeffrey Kindler - a lawyer who has been at the company for five years - it is getting one.

However, it is not clear whether Kindler is inaugurating a bold era in drug discovery or a period of creeping retrenchment. He is cutting several layers of middle management and bringing together scientists working on each of ten disease areas, from cancer to cardiovascular disease. In so doing, Kindler is not only seeking simplified logistics but also giving Pfizer's researchers a sense of collaborative ownership of the drug-discovery process. By dropping some discovery efforts entirely, he is acknowledging that the company can no longer afford to play every slot machine in the room. In the best of worlds, this will lead to greater focus and productivity, with the company doing better work in fewer disease areas.

But pessimists see an axe at work rather than a surgical scalpel - with more blows to follow at both Pfizer and its big competitors. These could well include sending a significant amount of early drug discovery to India, China or Eastern Europe, following the route that many clinical trials are already taking.

Observers also predict that big companies will increasingly rely on partnerships with small and mid-sized drug and biotechnology firms to generate drug candidates. If the research labs of Pfizer and its competitors cannot match the productivity of smaller, more flexible firms, it is not hard to imagine the bulk of discoveries being driven by such alliances. Then the big drug firms would be able to focus on what they do best: the heavy lifting of late-stage development and marketing.

Even then, sustaining profits won't be easy. With most, if not all, of the low-hanging fruit having been picked in the past quarter-century, even successful drugs are likely to generate revenues in the hundreds of millions, rather than billions, of dollars.

The industry must acknowledge this if it is to prepare for what is rapidly becoming the post-blockbuster era. All the signs say that companies need to shift their research sights to tailored drugs with smaller, targeted populations. These are cheaper to develop and, importantly, would face less market competition than the megablockbuster. Reading between the lines, Pfizer's announcement last week may have opened a door that leads in that direction. 